\title{
WORLD OF RESEARCH
}

The US reigns as the colossus but China is taking up ever more space, squeezing out European stalwarts.

HOW TO READ THIS GRAPH

Boxes are sized in proportion to

each country's fractional count (FC).

\section{Country FC}

Darker shades show the

global top 10 countries
Asia Pacific

West Asia

Africa

Europe

North America

South America

South Africa 89.08

Argentina 99.49

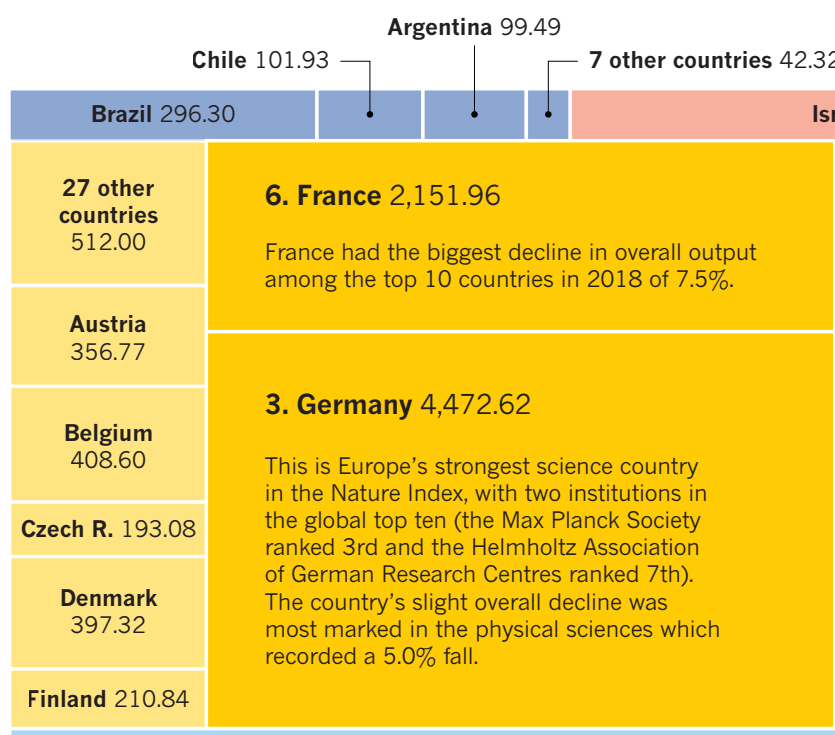

\section{China $11,183.75$}

Only China and Australia among the top 10 countries increased their adjusted FC in 2018. Chemistry is China's strongest discipline by far, with high-quality research output nearly double that of the physical sciences, and more than four times that of both the life sciences, and Earth and environmental sciences.

Of the top 50 institutions with the biggest rises in $\mathrm{FC}$ for the past three years, 41 were in China, including all of the top ten. The top five are shown here:
Israel 600.77

Saudi Arabia 131.73

18 other countries 154.16

Iran 110.50

\section{United Kingdom 3,667.40}

Life sciences, the UK's strongest subject field, rose by $3.6 \%$. The country's overall output fell by $4.0 \%$. The University of Oxford, its highest ranking institution in 2015 at 9th, has since dropped to 12th while

Cambridge rose from 10 th to 8 th over the same period.

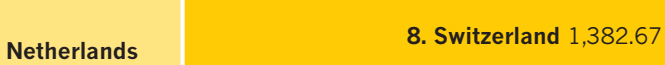

910.60

\begin{tabular}{|l|c|c|}
\hline Norway 191.89 & $\begin{array}{c}\text { Sweden } \\
616.63\end{array}$ & Spain \\
\hline Poland 226.24 & & \\
\hline
\end{tabular}

India 929.22
Total change in FC 2015-18

$\begin{array}{lllll}50 & 100 & 150 \quad 200 \quad 250\end{array}$

University of Chinese Academy of Sciences

Shanghai Jiao

Tong University

Tsinghua University

Nanjing University

University of Science and Technology of China

\begin{tabular}{|}
0 \\
\hline \\
\hline
\end{tabular}

India 929.22

5. Japan $2,987.34$

Japan's decrease in adjusted FC was exceeded only by France's among the top 10 countries. The University of Tokyo held on to 9th rank globally but its $12.0 \%$ decrease was the largest among the top 10 global institutions.

Singapore 597.81

9. South Korea $1,322.84$

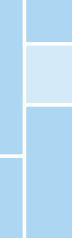

\section{United States $20,061.64$}

Despite the country's domination in terms of output, FC for the US

decreased in 2018 by more than most countries in the top 10 (see graph at right). Among US institutions, $47.6 \%$ had lower FC in 2018 than in 2015, compared with only $30.3 \%$ of Chinese institutions with lower FC for the period. Each of the top seven countries has held its rank for the past three years, while Switzerland has usurped South Korea for 8th, and Australia has displaced Spain for 10 th. Princeton University posted the biggest rise of all US institutions in FC 2015-2018 with 29.21, followed by Northwestern University (26.16) and University of California, Irvine (25.53)

\section{Change in adjusted FC 2017-18 (\%)}

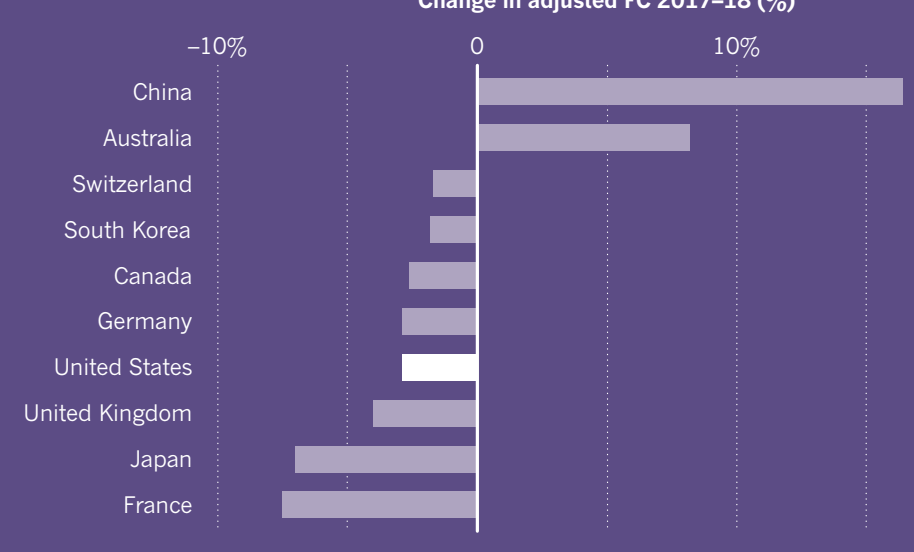


CORRECTION

In the Nature Index 2019 Annual Tables (Nature 570, S1-S6; 2019) the fractional counts, percentage changes and article counts used for the tables were incorrect, which affected the rankings of some institutions. The updated data, graphics and rankings can be found online at https:// www.nature.com/collections/fbfjafhcbb. 